\title{
NOTAS MUSICALES Y FUENTES ITALIANAS PARA EL ÁRBOL DEL MEJOR FRUTO, ACERCA DE UNA RECIENTE EDICIÓN CRÍTICA (IGNACIO ARELLANO, KASSEL, REICHENBER GER, 2009)
}

\author{
Iole Scamuzzi \\ Largo Montebello, 31 \\ 10124 Torino. Italia \\ arichel@hotmail.com
}

[Anuario calderoniano (ISSN: 1888-8046), 4, 2011, pp. 313-331]

La operación que Ignacio Arellano lleva a cabo en su edición crítica del auto sacramental calderoniano El árbol del mejor fruto va más allá de una mera recuperación del texto literario, puesto que no sólo examina la situación textual de la obra, sino que también ilumina sobre el interesante e insólito contexto cultural de su tema, ahondando en las fuentes y en la tradición de la leyenda del árbol de la cruz y de las visiones cristológicas de la reina de Saba.

La extensa introducción posee diferentes enfoques. Son marcadamente filológicas las primeras y las últimas páginas, en las que el estudioso, dentro de un estrecho diálogo con la crítica, afronta los problemas de la datación del auto sacramental y de la elaboración de un estema de los testimonios que han llegado hasta nosotros. Por lo que respecta a la datación, ninguna de las hipótesis formuladas por la críti- 
ca precedente parece convencer a Arellano. La Documentación de Pérez Pastor para la biografia de Calderón no ayuda a establecer una fecha para la obra, pero la falta de datos sobre los autos representados durante la celebración del Corpus Domini de Madrid del año 1677 permite a algunos estudiosos como Parker ${ }^{1}$ y con él Rull2 ${ }^{2}$, situar El árbol del mejor fruto en aquella ocasión. En apoyo de esta hipótesis se encuentra la loa que precede al auto en la edición de Pando (1717) de las obras de Calderón, en la que se menciona a Carlos II y algunos acontecimientos que el rey vivió en aquel año. Pero Arellano excluye que estos indicios puedan considerarse datos fiables para formular una hipótesis de datación: no en vano la cuestión de si las loas que preceden los autos en la edición de Pando son verdaderamente de Calderón, no puede considerarse concluida, incluso admitiendo que la loa en cuestión correspondiera realmente a El árbol del mejor fruto, dato que no puede darse por descontado. De todos modos, «las loas, como se puede advertir con mayores detalles en nuestras ediciones de $E l$ año santo de Roma y El año santo de Madrid, no sirven para datar los autos, salvo en casos muy excepcionales, que no es el de El árbol del mejor fruto» $^{3}$. Por último, las alusiones a Carlos II que Parker ha visto no pueden colocarse unívocamente en 1677. «En conclusión —afirma el estudioso- no se pueden precisar la fecha o circunstancias de estreno de El árbol del mejor fruto» ${ }^{4}$.

Un dato que sí contribuye a la colocación del auto por lo menos dentro de la fase más madura de la producción calderoniana es la convicción, compartida con la mayor parte de la crítica y en particular con Rulls, de que fue compuesta con posterioridad a la comedia sobre el mismo tema La sibila del Oriente, fechada verosímilmente en 1659-1661 (Valbuena Briones ${ }^{6}$ ). Rull habla de la comedia de este modo, y Arellano parece estar de acuerdo con él, en líneas generales:

Lo más sensato es que la comedia sea anterior, aunque no podamos precisar en cuánto tiempo, y como es cierto que la técnica y estilo nos

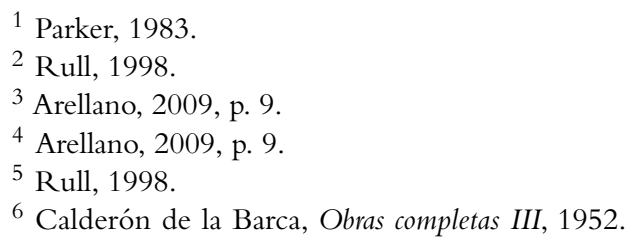


sitúan en una estética que corresponde a una de las épocas serenas y elaboradas de su autor, aunque menos evolucionadas que la del auto, las deducciones de Valbuena Briones nos parecen ciertamente encaminadas ${ }^{7}$.

La «nota al texto", parte conclusiva de la extensa introducción, retoma las cuestiones filológicas tras un amplio examen de las fuentes y de las variantes de la leyenda del árbol de la cruz y propone una cuidada lista de los testimonios del texto de El árbol del mejor fruto que han llegado hasta nosotros, un examen de las variantes y, para terminar, un estema. Arellano encuentra nueve testimonios, ocho manuscritos y una sola versión impresa de Pedro de Pando, incluida en Autos sacramentales, alegóricos y historiales del insigne poeta español Don Pedro Calderón de la Barca. Pedro de Pando sacó, entre 1717 y 1718, cuatro ediciones diferentes de esta colección de obras de Calderón, la primera en 1717, con la portada en rojo y negro, seguida en el mismo año por dos ediciones diferentes, ambas con variantes, con la portada negra; en 1718 salió una nueva edición en rojo y negro. Arellano considera que la edición más fiable es la primera, en rojo y negro de 1717, pero considera aún más relevante el ms. esp. 427.4 de la Biblioteca Nacional de París, realizado por un copista del que se desconoce el nombre pero cuya mano ha forjado «numerosas copias de comedias y autos, y que seguramente fue un amanuense profesional, quizá especializado en autos. Esta documentada familiaridad con el corpus sacramental me inclina, avanzo ya, a considerarlo como texto base» ${ }^{8}$.

En su estema, Arellano sitúa dos familias de testimonios que presuponen la existencia de dos arquetipos perdidos, llamados x e y. Tanto la edición Pando, como el manuscrito parisino descenderían directamente de y. La familia paralela $\mathrm{x}$ presupone dos testimonios perdidos, $\mathrm{x} 1 \mathrm{y} \mathrm{x} 2$, a los que corresponden respectivamente dos de los cuatro testimonios manuscritos que constituyen esta familia.

La parte central y más extensa de la introducción analiza la acción representada en el auto. Arellano usa de nuevo el material de Rull para afirmar que el auto es una versión más refinada desde los puntos de vista teatral y doctrinal, de la leyenda de la madera de la cruz, respecto a la comedia sobre el mismo tema La sibila del Oriente; de todas for-

\footnotetext{
${ }^{7}$ Rull, 1998, p. 344.

${ }^{8}$ Rull, 1998, p. 71.
} 
mas, las dos obras se parecen mucho y el estudioso presenta una lista de pasos que se presentan idénticos en la comedia y en el auto. Después divide la acción de El árbol del mejor fruto, carente de por sí de solución de continuidad, en secuencias basadas en el principio de la homogeneidad métrica y de la isotopía greimasiana (aquella propiedad típica de una unidad semántica que permite comprender un discurso como una unidad de significado); dichas secuencias serían tres fundamentalmente, ulteriormente divisibles en subsecuencias: Salomón y el templo; del reino de Saba al Líbano; la corte de Salomón y el árbol del mejor fruto. Tras estas consideraciones hay un resumen métrico.

Pero la parte más interesante de toda la introducción es, sin duda, la que reconstruye el recorrido literario de la leyenda de la madera de la cruz y de su asociación con la reina de Saba. Antes de desarrollar esta leyenda resulta necesario realizar un paralelismo entre Adán y Cristo, cosa que se encuentra a partir del evangelio apócrifo de Nicodemo (anterior al siglo v d. C.). Noé habría transportado a Judea los huesos del padre de todos los hombres y Sem los habría enterrado tras el diluvio; según las diferentes versiones del mito, Adán o su hijo Seth habían sacado del Paraíso terrenal tres semillas o tres ramas del árbol del pecado que, cuando se plantaron sobre los restos mortales de Adán, dieron lugar a un árbol prodigioso formado por tres tipos diferentes de madera. El mito presenta varias versiones también por lo que respecta a la naturaleza de las tres maderas, pero, de todas formas, las propiedades de cada material simbolizan cada una de las tres personas de la trinidad. La versión aceptada por Calderón describe el árbol del mejor fruto como una unión de cedro, palmera y ciprés: el primero, caracterizado por la resistencia y la fuerza, representa al Padre; el segundo, alto y glorioso, representa al Espíritu Santo y el tercero, que vela a los muertos, representa al Hijo, la única de las personas de la trinidad relacionada con la muerte. El mito de la madera de la cruz se relaciona con Salomón y la reina de Saba en la baja Edad Media, a partir de algunos textos de los siglos XII y XIII, sobre todo del área española, que Arellano identifica en la narración latina Poenitentia Adae, la Historia ecclesiastica de Pedro Comestor, La leyenda dorada de Jacobo de la Voragine, y otros.

Sólo el encuentro entre Salomón y la reina de Saba con motivo de la construcción del templo tiene su origen en la Biblia (Tercer Libro de los Reyes), pero no se encuentra ninguna mención del ár- 
bol prodigioso, ni de las visiones de la reina, que viaja a Jerusalén sólo para poner a prueba la sabiduría del rey. La reina se convierte en Sibila con las Antichitá giudaiche de Flavio Giuseppe, lugar en el que se menciona por primera vez el nombre de Nicaula, o Makeda.

La fuente más cercana a Calderón era probablemente el español Juan de Pineda, que a principios del siglo XVII publicaba un amplio tratado sobre la historia de Salomón, titulado Salomon praevius, sive de rebus Salomonis regis libri octo, que Arellano lee en una edición suiza de 1609, y que hemos consultado en la edición veneciana de Baglioni de 1611. Además del contemporáneo Gretser, autor de un célebre tratado De Cruce, Juan de Pineda afirma que ha extraído la mayor parte de la información sobre la reina de Saba y la leyenda de la madera de la cruz, de un libreto en veneciano vulgar del que da una detallada indicación bibliográfica:

Haec scripseram, cum sive casu, sive fato nescio quo, aliud agens, incido in bibliothecae illius Columbi Hispalensis Ecclesiae librum detritissimum, et obsoletissimum, prisca italica, et, ut videtur, veneta lingua conscriptum, excusum Taruisii, apud Miachaelem Manzolum: Anno MCCCCLXXVIII, die XIII Aprilis cui titulo Fioreto novello del testamento vecchio e novo'.

Arellano, aunque promete profundizar sobre el tema del Fioretto Novello en un segundo momento, luego prefiere dejarlo de lado, probablemente con miras a una posterior investigación sobre el tema. Se trata de un aspecto bastante interesante, en mi opinión, que merece más atención. Edoardo Barbieri ${ }^{10}$, en un ensayo en inglés, describe la obrita como una crónica de la antigüedad en la que se mezclan historias de origen bíblico y mitos de origen profano, además de narraciones procedentes claramente de las Metamorfosis de Ovidio. Explica que el Fioretto tuvo una gran fortuna editorial, pero recibió la desaprobación de la Iglesia, cuya condena causó la desaparición casi completa de la obra del mercado del libro. Barbieri cita la ilustre opinión de Pier Paolo Vergerio, en su comentario al índice de 1554, que pro-

9 Ioannis de Pineda Hispalensis, Salomon Praevius, sive de rebus Salomonis regis libri octo, Venetiis, MDCXI apud Thoman Ballionum, Liber V, caput XIV, 9 (p. 409).

10 Barbieri, 2001, pp. 111-133. 
hibía la traducción a lengua vulgar de la Biblia pero permitía la circulación de obras perniciosas como esta (cito en inglés, no habiendo podido consultar el original de la obra de Vegerio):

There is another, the title of which is Fioretti della Bibblia, where, amid an infinity of false doctrines and corrupt fables drawn (I say) word for word from the Metamorphosis (and narrated as if they truly happened at the time of the Old and New Testament), this is the most serious: it asserts the outright lie that Cain engaged with his son in the vice [i. e. Sodomy] so rife among you now that you have prohibited legitimate marriages [se refiere obviamente al clero católico, destinatario de su polémica]. And this book has been printed in Milan by Giovanni Antonio da Borgo ${ }^{11}$.

El tono airado de Vergerio se comprende mejor si se tiene en cuenta la enorme difusión que tuvo la estema: además de la edición milanesa que él señala y la que Pineda ha leído, hay que añadir otras dos, ambas de 1473, que encuentro citadas en el Repertorium Bibliographicum de Ludovico Hein (París, 1876):

7118. Fiore novello estratto dalla Biblia. Questo libro è chiamato fiore novello molto devoto da lezere cum certe predicatione e tuto il testamento vecchio commenzando da la creatione del mundo infina alla nativitá di Cristo. Haec in fronte. In fine: Qui finisse il libro chiamato Fioreto novello del testamento vecchio e novo; stampato en impresso in Venetia essendo principe Nicolo Trono. Per maistro Alvise da Sale medico da Padova nepote de lo venerabile misete pre Alexandro custode del domo 1473 adi 1 de Marzo.

7119. Opera, chiamata: Fioretti, extracti de la Biblia, secondo che contene nel testamento vecchio y nuevo, comenzando de la creazione del Mundo, per fina a la Natività de Cristo e molti miracoli che fece Iesu siando fantolino. In fine: Qui finisse il libro chiamato fioreto novello del testamento vechio e novo, V. 1473, a di 20 de Agusto $^{12}$.

${ }^{11}$ Vegerio, Repertorium Bibliographicum, in quo libri omnes ab arte typographica inven ta usque ad annum MD typis expressi, ordine alphabetico, vel simpliciter enumerantur vel ad curatius recensentur. Opera Ludovici Hein, Vol. I, pars II.

${ }^{12}$ Vegerio, Repertorium Bibliographicum, in quo libri omnes ab arte typographica inven ta usque ad annum MD typis expressi, ordine alphabetico, vel simpliciter enumerantur vel ad curatius recensentur. Opera Ludovici Hein, Vol. I, pars II, p. 386. 
Como Barbieri también señala, a pesar de esta riqueza editorial, el estema en poco tiempo desapareció casi por completo. En la actualidad no queda ningún ejemplar conservado en las bibliotecas italianas y la última referencia que se conoce se encuentra en un catálogo de papel de la Biblioteca Estense Universitaria de Módena de 1928, sin volver a aparecer en los catálogos más recientes ni en las últimas actualizaciones informáticas de los patrimonios libreros italianos. Por lo demás, las palabras de Pineda no dejan lugar a dudas sobre el destino reservado al tratado: ya a principios del siglo XVII, el estudioso encontraba por casualidad - sive casu, sive fato nescio quo- un ejemplar detritissimum, et obsoletissimum, en la biblioteca de Hernando Colón y consideraba el hallazgo excepcionalmente afortunado. Pineda encuentra que la obra posee originalidades respecto a las versiones del árbol de la cruz y de la reina de Saba que Gretser y los textos autorizados por la Iglesia cuentan, hasta el punto que decide examinarla detenidamente para buscar por todas partes en el texto las referencias al tema estudiado y reordenarlas en una única narración en latín:

Multis, ut videtur, sive haebreorum traditionibus et fabulis, sive incertis et apocryphis narrationibus, sive admirandis aliis minus notis, minusque pervulgatis ad priscas librorum sanctorum historias observationibus refertum. In eo statim meum quaero Salomonem, video et lego hanc ipsam rem reginae Saba, et ligni sanctae crucis; sed eo loco non tam plene ac luculenter expositam, quam indicatam, et quaeri iussam aliis totius operis sparsim locis. Ergo quaerenda mihi fuit, et frustratim carpenda evoluto universo volumine, et iam inde ab Adamo ducto filo totius narrationis. Que cum aliter quam apud latinos, et quam apud Graecum illum nostri Gretferi ex Bibliotheca Augustana, in hac Hispalensi nostra habeatur, e re et oblectamento lectoris fore putavi, si integra hoc loco latine descriverem ${ }^{13}$.

La historia de la madera de la cruz que cuenta Pineda a partir del libreto véneto posee muchos paralelismos con la que Calderón acepta y pone en escena: Adán, moribundo, manda a su hijo Seth al Paraíso Terrenal para que le pida a San Miguel el óleo de la misericordia. Pero

13 Ioannis de Pineda Hispalensis, Salomon Praevius, sive de rebus Salomonis regis libri octo, Venetiis, MDCXI apud Thoman Ballionum. 
el arcángel explica a Seth que dicho ungüento todavía no está disponible para el hombre y en cambio, le enseña el árbol del pecado, que tiene que transformarse en árbol de la salvación. Le regala tres semillas, que tendrán que sembrarse bajo la lengua de Adán tras su muerte, que ya ha tenido lugar estando ausente su hijo. Adán es enterrado con las semillas en la boca, y de su cráneo surge un árbol frondoso y prodigioso. Jericó, hijo de Noé, trasplantó el árbol en el desierto. Al final Moisés lo trasplantó en el monte Thabor. La madera la reconoce y encuentra David en una visión divina, el cual solemnemente lo deja a Salomón el día de su llegada al trono, junto a la profecía según la cual una mujer resolverá el enigma de su portentosa naturaleza. La reina de Saba, Sibila de Oriente, visita a Salomón y por medio de una visión reconoce el árbol que da la madera de la cruz. Salomón, conmocionado por la visión del hijo de Dios asesinado por mano de su pueblo, arroja la madera al río Cedrón creando de este modo la piscina probática, de la que surgirá el tronco poco antes de la Pasión para volver a formar parte del templo y de allí se tomará para tallar la cruz.

Sin contar la conclusión de la historia — el Rey adora la madera sagrada en Calderón-, la versión que propone a partir del florilegio italiano coincide con la del comediógrafo. En primer lugar, los tipos de madera que componen el árbol de la cruz son Cedro, Palmera y Ciprés y se identifican con las tres personas de la trinidad:

Primus, cedrus erat arborum omnium celsissima, Dei Patris symbolum. Secundus, cupressus odoratissima, et inter arbores omnes ramosissima, filii symbolum. Tertium, palma spississima habens folia, et ferens aloen, signum spiritus sancti (liber V, cap. IX, 9, p. 409).

SABÁ

[...] estas ${ }^{14}$ pues, sembradas dieron sobre el sepulcro de Adán en palma, ciprés y cedro el árbol que a Jericó cupo en el repartimiento, que del mundo y del cadáver entre sus hijos y nietos

${ }^{14}$ Se refiere a las semillas que Seth entierra en la boca de su padre. 
hizo Noé [...]

(vv. 1835-1842 15 )

Además, la profecía de David según la cual una mujer y una madera legitimarían el reino de Salomón por voluntad de Dios, se menciona varias veces en el auto:

SALOMÓN

Partid en paz, que no sé,

qué nuevo espíritu en mí

dice que habéis de traerme

el tesoro más feliz

del Líbano y de Sabá

Pero, ¿qué mucho, si oí,

que a la gran Jerusalén

el mayor ha de venir

en una mujer y un tronco

de la casa de David?

(vv. 311-320)

SALOMÓn Los dos me habéis logrado

las dos cosas que más he deseado

que no sé lo que infiero

en mí de una mujer y de un madero

que han de ilustrar con majestad no escasa

de Dios el templo y de David la casa

(vv. 1095-1100)

Por tanto, la damnatio memoriae del florilegio italiano llevada a cabo por los contemporáneos de Vergerio ya había agotado su misión en tiempos de Juan de Pineda ${ }^{16}$, pero el erudito español cambia su des-

15 Son los mismos versos que aparecen en la comedia La Sibila de Oriente.

16 De hecho, el parecer que Pineda da sobre la obrita difiere completamente de la opinión negativa de Vergerio: las historias que se cuentan son de origen variado y a menudo apócrifo, pero no se halla nada contrario a la doctrina, por lo menos por lo que respecta a la leyenda de la madera de la cruz; por lo que cada lector debe juzgar por sí mismo si está interesado en la lectura: «Ego ut de tota narratione censeam, video in illa particulatim illos omnes convenire quos peculiaribus suis narrationibus dissentire nuper dicebamus. Et sane nihil in illa absurdi, nihil contra pietatem, et religionem inesse arbitror; ceterum nihil certum, incerta et apocrypha omnia. De quibus suum cuique iudicium». 
tino cuando le entrega a Calderón algunos restos de ella por medio de su síntesis latina. No hay duda de que en alguna biblioteca europea se conserva todavía algún ejemplar, probablemente manuscrito; el hallazgo y el estudio de este texto serían de extremo interés en el ámbito de la difusión de contenidos bíblicos en lengua vulgar en los países no protestantes de Europa, como sugiere Edoardo Barbieri; así como, en nuestra opinión, para entender cómo ciertos núcleos de la mitología cristiana se ponían a disposición de los artistas para que realizaran nuevas elaboraciones estéticas (de carácter literario, musical, figurativo, teatral) por caminos distintos a los ortodoxos de los textos oficiales.

Desgraciadamente de la obrita italiana no sobrevive, a través de Pineda, más que el material relacionado con el ciclo salomónico y la casa de David. Como señala Rull en el ensayo que Arellano menciona y cita en diversas ocasiones, las leyendas y las historias bíblicas relacionadas con David y Salomón habían suscitado el interés de los grandes comediógrafos españoles de principios del siglo XVII: Calderón les dedicó, en colaboración con Tirso de Molina (La venganza de Tamar), una trilogía (Los cabellos de Absalón; La sibila del Oriente; El árbol del mejor fruto) de tono trágico, con la intención de indicar que Salomón era un rey elegido por Dios y no por los hombres; el mismo Lope de Vega escribió sobre el hijo de David una comedia que no ha llegado hasta nosotros (El Templo de Salomón). Paralelamente, también en Italia se da una rica cosecha de dramas salomónicos y una consistente fortuna de la leyenda del árbol de la cruz.

Entre los años sesenta y setenta del siglo XVII, se encuentran hasta diecisiete obras sobre este tema, entre dramas musicales, oratorios sacros y representaciones sacras. Daré sólo algunos ejemplos. De los primeros que se ocuparon del tema de El árbol del mejor fruto fue el maestro de capilla de la corte de Viena Antonio Draghi, que en 1691 ponía en escena en Viena la sagrada representación I frutti dell'albero della croce y la noche del Viernes Santo de 1699 «Il secondo Adamo disformato per formare il primo, rappresentazione sacra al Ss.mo Sepolcro nella Cesarea cappella di Leopoldo I $»^{17}$. En 1693 Bernardo Pasquini ponía en escena en el Oratorio de San Filippo Neri de Florencia,

17 Por lo que respecta a esta información y a las siguientes relacionadas con los libretos italianos ver, en orden alfabético por título, Sartori, 1994. 
un oratorio a cuatro voces titulado Salomone. De 1679 es el Salomone Amante de Giacomo Antonio Bergamori con música de Giovanni Paolo Colonna «maestro di cappella della perinsigne collegiata di S. Petronio di Bologna e cantato nella sala della musica di S. Petronio la sera del 16 Marzo». En 1705, Fux musicaba el oratorio La regina di Saba del abad Pier Maria Ruggieri, de nuevo en la capilla dedicada a Leopoldo I en Viena.

Pero no faltan las obras anónimas, tan comunes en el teatro musical de la época: la obra más antigua de las que nos hemos ocupado está dedicada precisamente a la madera de la cruz, se trata del libreto L'albero della vita ritrovato, representado en Lucca «nella solennità celebrata dalle suore di S. Maria Cortelandini nella chiesa dei Molto Reali Principi della Congregazione della Madri di Dio l'anno 1664»; la más tardía es el monumental Salomone esaltato al trono e destinato edificatore del tempio di Gerosolima, "Componimento sacro drammatico da cantarsi nelle sere del dí 3 e 8 Dicembre 1775 in occasione della solenne apertura del nuovo oratorio e fabbrica de' M.M. R.R. P.P. Di San Filippo Neri di Firenze sotto i faustissimi auspici di Sua Altezza Reale Pietro Leopoldo principe reale d'Ungheria e di Boemia»; entre cuyos personajes aparecen Salomón, David, Betsabé y el sacerdote Natán.

No sorprende en absoluto que el ciclo salomónico haya tenido un mayor eco en Italia en el campo del teatro musical, puesto que también las obras contemporáneas españolas gozaban de un rico acompañamiento musical, que difería en muchos puntos del de los dramas musicales italianos pero que, no por ello, revestía un papel de menor importancia. El amplio análisis cultural de la edición crítica de Arellano anima al estudioso de Calderón a analizar El árbol del mejor fruto desde todos los puntos de vista posibles, y aunque no se le conceda igual importancia al universo musical que al literario, una línea de investigación que completaría la visión de conjunto de la obra, sería la relacionada con la música que, como ya se ha dicho, acompañaba tanto a La Sibila del Oriente como a El árbol del mejor fruto.

Musicólogos e historiadores del teatro señalan con insistencia el papel fundamental que la música poseía en el teatro de Calderón; fue precisamente a partir de sus obras cuando el teatro del Siglo de Oro español empezó a competir con el italiano por la riqueza de la presencia musical y cuando comienza el género de la zarzuela, de argumento cómico o divino. Aunque las piezas musicales que acompaña- 
ban a la obra teatral a veces se extendieran a la totalidad de versos que la componían - como en el conocido caso de la calderoniana Celos aun del aire matan - la ópera musical a la española de esa época no puede compararse con la italiana como si se tratara de un fenómeno análogo, ni debe considerarse derivante de ese modelo, porque los criterios de entonación eran muy diferentes ${ }^{18}$.

La tradición operística italiana anterior a la reforma de Gluck distinguía los dos momentos musicalmente alternativos del área y del recitativo. La primera, de contenido lírico y secundaria con respecto al desarrollo de la acción, ofrecía al compositor y al cantante un espacio para expresarse libremente y para profundizar musicalmente en los matices de los sentimientos del personaje. El recitativo, en cambio, funcional con respecto al desarrollo de la trama, al principio se llevaba a cabo rítmicamente sin acompañamiento (recitativo seco) para entonarse más tarde con sobria eficiencia narrativa (recitativo acompañado). Las obras teatrales de Calderón que dan lugar al género de la zarzuela actúan de manera contraria, dejando que el área se acerque al monólogo hablado y, en cambio, musicando llamativamente los diálogos de los personajes que conducen la acción a su desenlace.

Tanto las comedias como los autos de Calderón preveían música en muchas de sus partes, tanto que Miguel Querol, uno de los primeros y más ilustres estudiosos del teatro musical calderoniano, afirmaba en varias sedes críticas que «Calderón, si viviera, no permitiría que fuesen representados sin música, porque ésta en Calderón no es un elemento de adorno y de relleno, sino un elemento básico de la subestructura de su teatro» ${ }^{19}$. El auto sacramental es un género que se presta especialmente a la entonación musical por el alto nivel alegórico de los acontecimientos narrados, que desvincula a los personajes de estrechas exigencias de verosimilitud y les permite utilizar el atractivo de la voz. La música en estas representaciones es moralmente neutra y por esto la pueden usar tanto personajes alegóricos positivos para impartir enseñanzas, como alegorías negativas (como en el caso de la Idolatría en El árbol del mejor fruto) para seducir a los demás personajes y al público. Los autos de Calderón a menudo retoman el tema,

18 Con respecto a la fortuna de los temas y de los textos calderonianos en el teatro con música italiano, ver los trabajos de Profeti, 1996 y 2009.

${ }^{19}$ Querol Gavaldá, 1981, p. 8. 
el contenido y, en ocasiones, secciones poéticas completas de anteriores comedias o dramas mitológicos, de los que heredan amplios pasajes tanto textuales como musicales, parcialmente remodelados para adaptarse al contexto alegórico-didáctico del auto. Carmelo Caballe$\mathrm{ro}^{20}$ llama a esta técnica centonización y conversión a lo divino, porque retoma algunos versos de las comedias y los adapta al contexto alegórico del auto. Por este motivo, en muchos casos en los que la partitura del auto sacramental no ha llegado hasta nosotros o lo ha hecho sólo en parte, la música de la comedia correspondiente (en este caso La sibila del Oriente) resulta pertinente para el estudio del auto.

A pesar de esta reconocida importancia del fenómeno musical dentro del mundo del teatro calderoniano, las fuentes para reconstruir las partituras y las modalidades de ejecución, son muy limitadas. Sólo en un caso disponemos de una partitura completa, en la comedia arriba citada Celos aun del aire matan, que está considerada la primera zarzuela y para la que se conserva la música de Juan Hidalgo, músico que trabajaba con Calderón. De las demás comedias y autos se conservan sólo algunos números musicales, que han llegado a nuestros días a través de antologías manuscritas de la primera mitad del siglo XVIII. Se trata de colecciones de piezas de origen tanto teatral como cancioneril, que habían gustado al público y, por ese motivo, habían sido transcritas, para poderlas conservar y ejecutar con acompañamiento de bajo continuo, como música de cámara. Por lo tanto, las fuentes para estudiar la música en Calderón, más allá de la partitura de Celos aun del aire matan, se pueden reducir a tres testimonios, que conservan en total seiscientas piezas, en su mayoría de origen teatral:

-El manuscrito Gayangos-Barbieri, de propiedad de Barbieri, utilizado por Pedrell para su Teatro lírico Español anterior al siglo $X I X^{21}$, que contiene música para comedias representadas entre las últimas décadas del siglo XVII y el primer lustro del siglo XVIII;

-El manuscrito de la Novena, fechado por Louise Stein ${ }^{22}$ entre 1710 y 1720, fue descubierto por Barbieri en 1886 y descrito por José

20 Caballero Fernández-Rufete, 2003.

21 Pedrell, 1895-1898.

22 Stein, 1980. 
Subirá en 194923. Querol lo usó para transcribir todos los números musicales correspondientes a obras de Calderón para su obra Teatro Musical de Calderón. En su interior se encuentran siete números musicales para La sibila del Oriente, que Querol atribuye al compositor de finales del XVII José Peyró, autor de otras piezas contenidas en el manuscrito, basándose en «un fragmento melódico armónico en el bajo del acompañamiento que aparece en distintas obras, unas con el nombre de Peyró y otras anónimas» ${ }^{24}$. La crítica posterior pondrá en entredicho esa atribución pero, de todos modos, hay que señalar que José Peyró pertenecía a la generación inmediatamente posterior a la de Calderón y, contrariamente a Juan Hidalgo, nunca pudo trabajar en contacto con el comediógrafo. Por lo tanto, sus composiciones calderonianas, incluida La sibila del Oriente en el caso en el que la atribución de Querol fuera acertada, se deben considerar póstumas y no pudieron recibir la aprobación de Calderón;

-El Manuscrito Guerra, compilado por Miguel de Guerra en torno a 1680, que contiene música de los treinta años anteriores, es el único testimonio contemporáneo de Calderón. Contiene cien piezas para soprano y bajo continuo, de los que una cuarta parte son de origen teatral.

Alejandra Pacheco, en su introducción a la edición crítica y musical del auto de Calderón Primero y Segundo Isaac ${ }^{25}$, señala que existe una permeabilidad recíproca, a lo largo del siglo XVII y a principios del siglo XVIII, entre el repertorio teatral y el repertorio de música de cámara. No en vano muchos de los números musicales presentes en las comedias, versos incluidos, ya se encontraban en los cancioneros del siglo XVI y se volvían a usar en el teatro porque eran conocidos y apreciados por el público, sobre todo en situaciones tópicas como, por ejemplo, las escenas pastoriles o de bodas. A esta invasión de la música de cámara en ámbito teatral, corresponde un movimiento igual y contrario, según el cual, piezas especialmente exitosas de las comedias musicales pasaban a formar parte de antologías en obras misceláneas como las que hemos enumerado más arriba, con acompañamiento de

23 Subirá, 1949.

24 Querol Gavaldá, 1981, p. 36.

25 Pacheco, 2003. 
bajo continuo, para su uso en los salones y para la ejecución más bien doméstica.

Por tanto, las piezas musicales se retomaban y se volvían a proponer, con o sin variaciones del texto, en diversas ocasiones, en vida de Calderón pero sobre todo tras su muerte, cuando sus autos se volvían a musicar para representarse con motivo de las festividades madrileñas del Corpus Domini. Por lo que es legítimo suponer que, aunque no haya llegado hasta nosotros ningún número musical de $E l$ árbol del mejor fruto, por lo menos en las partes del texto con versos idénticos a los de La sibila del Oriente, también la música que acompañaba a los versos se haya utilizado para el auto, en algún momento de su representación escénica. Un análisis de los textos alineados de los números musicales transcritos por Querol y de los momentos respectivos de La sibila del Oriente y de El árbol del mejor fruto pone en evidencia dos puntos de contacto, en los que los versos cantados de la comedia podían transportarse sin cambiar nada, ni siquiera la música, al auto. Se trata del número 3 de Querol, correspondiente a los vv. 321-326 de El árbol del mejor fruto:

$$
\begin{aligned}
& \text { La sibila soberana } \\
& \text { de la grande india oriental } \\
& \text { la emperatriz de Etiopía } \\
& \text { y la reina de Sabá, } \\
& \text { inspirada de un fervor } \\
& \text { que le asiste celestial } \\
& \text { se ha retirado a saber } \\
& \text { secretos que rivelar. }
\end{aligned}
$$

El texto del auto presenta una cuarteta más respecto a la comedia (vv. 321-332):

MúsICA

\author{
La sibila soberana \\ de la gran India oriental \\ emperatriz de Etiopía \\ Reina invicta de Sabá \\ Inspirada del fervor \\ Que la asiste celestial \\ Retirada está a inquirir \\ Secretos del bien y el mal, \\ que no ha para quien
}


aspira a deidad

mejor compañía

que la soledad.

Querol transcribe la partitura (nueve compases a cuatro voces) asignando el mismo texto a todas las voces, el de la primera cuarteta, pero señala que: «el manuscrito aplica la letra de la primera cuarteta a la cuarta voz, y el texto de la segunda cuarteta a la voz tercera, así el texto está completo a la vista en la partitura» ${ }^{26}$. Esta superposición de textos corresponde al principio de la missa brevis, que prevé que distintas voces pronuncien contemporáneamente diferentes partes del texto litúrgico, para poderlo completar en un espacio de tiempo limitado. Por lo tanto Peyró, o alguien en su lugar, tenía la posibilidad de que las cuatro voces repitieran la misma música tres veces, cantando las tres cuartetas sucesivas, como indicaría la transcripción de Querol, o bien superponiendo el texto de la primera cuarteta, cantado por las dos primeras voces, al de la segunda y tercera cuarteta, cantado por la tercera y la cuarta voz. Por eso, la presencia en el auto de una cuarteta más respecto a la comedia no debía crear problemas de adaptación musical, puesto que se podía asignar a una de las voces sin alterar ni una nota del fragmento ni su duración.

Más interesante es el caso del número 5, que corresponde a los versos 1252-1255 y 1273-1276 de El árbol del mejor fruto, que tanto en la comedia como en el auto, la Música los canta cuando entra en escena la reina de Saba, que piensa que está entrando en Jerusalén:

Morena soy, pero hermosa

hija de Jerusalén,

morena soy, pero hermosa,

bien podéis venirme a ver.

Se trata de un villancico de nueve compases a cuatro voces, repetido ad libitum para acompañar los movimientos escénicos, que se basa en los famosos versos del Cantar de los cantares I, 5:

${ }^{26}$ Querol Gavaldá, 1981, p. 19. La partitura del número 3 de La Sibila del Oriente se encuentra en la p. 49. 
Nigra sum sed formosa, filiae Hierusalem sicut tabernacula Cedar sicut pelles Salomonis

Querol $^{27}$ define villancico como un canto en lengua vulgar para una voz o varias basado en temas o textos sagrados; se denomina también tono a lo divino y abundan en los cancioneros. Estos versos, en su versión latina, ya se habían cantado varias veces tanto en Italia como en España, entre finales del siglo XVI y principios del XVII. Hay que recordar los motetes de Adriano Banchieri y de Tomás Luís de Victoria, pero sobre todo el de Palestrina, que el compositor volvió a usar para su misa Nigra sum ${ }^{28}$. La versión en castellano de Calderón se musicalizó, según Querol, por lo menos en dos ocasiones: la primera, con música de Peyró, para La sibila del Oriente y El árbol del mejor fruto, versión que el mismo Querol transcribe del Manuscrito de la Novena, y una segunda vez por Torrejón de Velasco, para La púrpura de la rosa.

No hay duda de que, a pesar del largo recorrido documental realizado, no se puede reconstruir mucho de la música que acompañaba a El árbol del mejor fruto, pero, a pesar de eso, para completar el discurso empezado por Arellano sobre el auto, hay que recordar que la música lo acompañaba y en buena parte, iba más allá de las intervenciones del personaje-coro que lleva su nombre. Como opinaba Querol $^{29}$ :

La música, en toda la producción escénica de Calderón, es tan esencial que podríamos decir que Calderón necesita la cooperación de la música como el aire que respira. La música en Calderón es la encarnación de la quinta esencia de lo que se representa, es la expresión del pensamiento transcendental de su autor, del mensaje que el arte del dramaturgo envía al espectador, a la humanidad entera. Especialmente la música de sus coros o cuatros, en los que la mayor parte de veces los músicos son invisibles, encarna la voz impersonal del destino, la voz abstracta de la conciencia moral, la voz extraterrestre que avisa, aconseja e incita al hombre a realizar una acción determinada o, al contrario, a evitarla. Sobre todo en los autos sacramentales, encarna la confesión de la fe, el grito de

27 Querol Gavaldá, 1981.

${ }^{28}$ Hay que recordar que la misa reproduce sólo los temas musicales del motete, sustituyendo por completo el texto con el litúrgico.

29 Querol Gavaldá, 1981, p. 7. 
triunfo de esta misma fe y la convicción del creyente en los misterios de que el auto trata.

En conclusión, la edición crítica de Ignacio Arellano, además de ofrecer un texto filológicamente seguro de El Árbol del mejor fruto, abre una ventana fundamental hacia el contexto cultural que rodeaba a la puesta en escena del auto; además de animar a realizar otras investigaciones sobre los diversos temas tratados: la popularidad de las historias salomónicas en el teatro del Siglo de Oro, el desarrollo gradual y la consolidación de la leyenda del árbol de la cruz, el interés por la reina de Saba y por su transformación de sabia soberana de la Biblia a adivina del destino del pueblo de Israel. Esta edición constituirá en el futuro el punto de partida imprescindible para llevar a cabo cualquier estudio sobre El árbol del mejor fruto o sobre La sibila del Oriente, además de una valiosa brújula con la que orientarse entre los textos que han contribuido a la difusión apócrifa y profana de las historias de Salomón y de la leyenda del árbol de la cruz desde la antigüedad tardía hasta el Siglo de Oro. 


\section{BibLIOgRAFÍA}

BARBIERI, E., "Tradition and change in the spiritual literature of the Cinquecento", en Church, censorship and culture in early modern Italy, ed. G. Fragnito, Cambridge, Cambridge University Press, 2001, pp. 111-133.

Caballero Fernández-Rufete, C., "La música en el teatro clásico», en Historia del teatro español, coord. J. Huerta Calvo, Madrid, Gredos, 2003, vol. 1, pp. 677-716.

Calderón de la Barca, P., El árbol del mejor fruto, ed. I. Arellano, Kassel, Reichenberger, 2009.

- Obras Completas, Vol. III: Autos Sacramentales, ed. Á.Valbuena Briones, Madrid, Aguilar, 1952.

Pacheco A. (ed.), La música para el auto sacramental de Calderón de la Barca "Primero y segundo Isaac», Kassel, Reichenberger, 2003.

Pando y Mier, P. de (ed.), Autos sacramentales, alegóricos y historiales del insigne poeta español don Pedro Calderón de la Barca, Madrid, Manuel Ruiz de Murga, 1717.

Parker, A. A., Los autos sacramentales de Calderón de la Barca, Barcelona, Ariel, 1983.

Pedrell, F., Teatro lírico español anterior al siglo XIX, La Coruña, Canuto Berea y Compañía, 1895-1898.

Pineda Hispalensis, I. de, Salomon Praevius, sive de rebus Salomonis regis libri octo, Venetiis, MDCXI apud Thoman Ballionum.

Profeti, M. ${ }^{a}$ G., Tradurre, riscrivere, mettere in scena, Firenze, Alinea, 1996.

- Commedie, riscritture, libretti: la Spagna e l'Europa, Firenze, Alinea 2009.

Querol Gavaldá, M., Teatro musical de Calderón, Barcelona, CSIC, 1981.

Rull, E., "Creación y evolución en la trilogía salomónica calderoniana", Anuario de estudios filológicos, 21, 1998, pp. 329-352.

SArtori, C., I libretti italiani a stampa dalle origini al 1800, Cuneo, Bertola \& Locatelli editori, 1994.

STEIN, L., "El manuscrito novena: sus textos, su contexto histórico-musical y el músico Joseph Peyró», Revista de musicología, 3, 1980, pp. 197-234.

Subirá, J., "Un manuscrito musical de principios del siglo XVII», Anuario Musical, 4, 1949, pp. 181-191.

Vergerio, P. P., Repertorium Bibliographicum, in quo libri omnes ab arte typographica inventa usque ad annum MD typis expressi, ordine alphabetico, vel simpliciter enumerantur vel adcuratius recensentur, opera Ludovici Hein, vol. I, pars II, Parisii, 1876. 